\title{
Convective-stratiform rainfall separation of typhoon Fitow (2013): A 3D WRF modeling study
}

\author{
Huiyan $\mathrm{Xu}^{1,2}$, Guoqing Zhai ${ }^{1, *}$, and Xiaofan $\mathrm{Li}^{1}$ \\ ${ }^{1}$ Department of Atmospheric Sciences, School of Earth Sciences, Zhejiang University, Hangzhou, China \\ ${ }^{2}$ Zhejiang Institute of Meteorological Sciences, China Meteorological Administration, Hangzhou, China
}

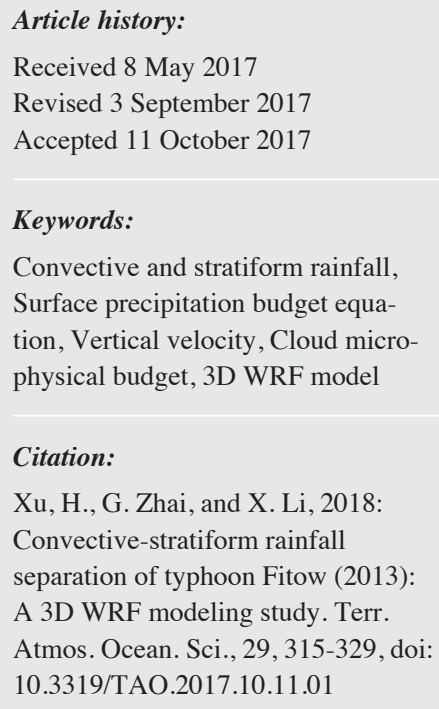

Xu, H., G. Zhai, and X. Li, 2018: Convective-stratiform rainfall separation of typhoon Fitow (2013): A 3D WRF modeling study. Terr. Atmos. Ocean. Sci., 29, 315-329, doi: 10.3319/TAO.2017.10.11.01

\begin{abstract}
Surface precipitation budget equation in a three-dimensional (3D) WRF model framework is derived. By applying the convective-stratiform partition method to the surface precipitation budget equation in the 3D model, this study separated convective and stratiform rainfall of typhoon Fitow (2013). The separations are further verified by examining statistics of vertical velocity, surface precipitation budget, and cloud microphysical budget. Results show that water vapor convergence moistens local atmosphere and offsets hydrometeor divergence, and producing convective rainfall, while hydrometeor convergence primarily supports stratiform rainfall, since water vapor divergence and local atmospheric drying generally cancelled out. Mean ascending motions are prevailing in the entire troposphere in the convective region, whereas mean descending motions occur below $5 \mathrm{~km}$ and mean ascending motions occur above in the stratiform region. The frequency distribution of vertical velocity shows vertical velocity has wide distribution with the maximum values up to $13 \mathrm{~m} \mathrm{~s}^{-1}$ in the convective regions, whereas it has narrow distribution with absolute values confined within $7 \mathrm{~m} \mathrm{~s}^{-1}$ in the stratiform region. Liquid cloud microphysics is dominant in convective regions and ice cloud microphysics is dominant in stratiform regions. These indicate that the statistics results are generally consistent with the corresponding physical characteristics of the convective-stratiform rainfall structures generalized by previous studies.
\end{abstract}

\section{INTRODUCTION}

Precipitation and associated clouds are generally partitioned into convective and stratiform types. Partitioning of rainfall and clouds helps to the analysis of rainfall processes, which improves the understanding of thermal, water vapor and cloud microphysical processes connected with convective developments (Sui et al. 2007). Convective rainfall and stratiform rainfall are different from each other in several aspects. Convective precipitation is primarily associated with the accretion of cloud water by rain particles in strong updraft flows, while stratiform precipitation is mainly related to vapor deposition on ice crystals and the melting of snow and graupel to rain (Houghton 1968; Sui et al. 2007; Li et al. 2014). Precipitation from the deep convective regions is associated with stronger upward motions, larger reflectivity gradient and higher rain rate than that from the stratiform

\footnotetext{
* Corresponding author

E-mail:zhaigq@zju.edu.cn
}

regions (Schumacher and Houze 2003; Li et al. 2014).

The convective-stratiform precipitation partitioning method has been developed in the past decades based on observations. A simple method to distinguish convective rainfall from rain gauge data is to utilize a rain threshold (Austin and Houze 1972; Balsley et al. 1988; Johnson and Hamilton 1988). As radar observations widely used, the convectivestratiform precipitation partitioning method was developed with radar data (Houze 1973; Gamache and Houze 1982; Churchill and Houze 1984; Steiner and Houze 1993; Steiner et al. 1995; Awaka et al. 1997; Yuter and Houze 1997; Powell et al. 2016), the neural network approach (Anagnostou 2004), and a fuzzy logic algorithm (Yang et al. 2013). Biggerstaff and Listemaa (2000) improved the performance of radar echo categorization by employing a modified algorithm for the partitioning of radar reflectivity into convective and stratiform rain classifications. In addition to radar data, other observations applied to investigate convective 
and stratiform precipitation include satellite data and Doppler wind profiler data (Adler and Negri 1988; Williams et al. 1995; Hong et al. 1999).

The convective-stratiform rainfall separation methods have also been developed based on the model simulation data (Churchill and Houze 1984; Tao and Simpson 1989; Tao et al. 1993; Caniaux et al. 1994; Sui et al. 1994; Steiner et al. 1995; Xu 1995; Tao et al. 2000; Lang et al. 2003). Motivated by the idea that the ratio of ice water path to liquid water path is one of the most important quantities reflecting the development of convective and stratiform rainfall (Sui and Li 2005), Sui et al. (2007) proposed a new convective-stratiform rainfall separation approach by analyzing the ratio. The method possesses the advantage over other techniques that it employs only cloud information within individual column instead of the ambient information. By using a diagnostic surface precipitation budget equation (Gao et al. 2005b), Shen et al. (2010) separated rainfall into eight types and Li et al. (2014) combined these rainfall types into convective-stratiform rainfall according to rain microphysical budget and vertical profile of vertical velocity, which is a physics-based rainfall separation scheme. However, such rainfall partitioning method is based on the 2D cloudresolving model (CRM) simulations. Though 2D and 3D CRM simulations show similarities (Tao and Soong 1986; Tao et al. 1987), yet 2D and 3D model simulations reveal major differences in dynamics (Xu et al. 2002). Gao et al. (2005a) and Gao (2007) showed that convection is highly correlated with the horizontal components of the dynamic vorticity vector in 3D model framework, whereas it is highly correlated with the vertical components of the dynamic vorticity vector in $2 \mathrm{D}$ model framework, because dominant items in horizontal components of the 3D dynamic vorticity vector are removed in the 2D model framework. Stephens et al. (2008) found the differences in precipitable water and precipitation variability and upper-tropospheric cloud fraction and condensate amount between 2D and 3D model simulations. In addition to difference in dimensionality, open lateral boundaries are allowed in some 3D models (e.g., The Weather Research and Forecasting Model), whereas periodic lateral boundaries are used in the 2D cloud-resolving models. These differences between $2 \mathrm{D}$ and $3 \mathrm{D}$ model results indicate that it is necessary to examine whether the separation method proposed by Shen et al. (2010) and Li et al. (2014) was applicable for 3D model simulations.

Typhoon Fitow (2013) struck China during 6 - 8 October 2013 and brought torrential rainfall and strong wind gusts, causing severe economic impacts (Yu et al. 2014; Lou and Li 2016). Bao et al. (2015) diagnosed the heavy rainfall caused by Fitow (2013), their results indicate that the interactions between midlevel embedded moist potential vorticity (PV) from Fitow's circulation, low-level warm moist inflow from the east, midlevel inflow from nearby Typhoon Danas (2013), and PV from the midlatitude trough mainly account for it. A relatively detailed description of the Fitow case may refer to the study by Yu et al. (2014), Xu et al. (2016), and Xu and Li (2017).

Typhoon is developed over warm waters involves organized deep convections in a favorable atmospheric environment. Many studies have investigated physical mechanisms contributing to the typhoon heavy rainfall by conducting water budget analysis (Yang et al. 2008, 2011; Huang et al. 2014). Motivated by the consideration that both deep convections and strong divergence occur in typhoon system, it is natural to ask the following questions. Firstly, whether convective rainfall and stratiform rainfall are equally important in producing strong rainfall during typhoon Fitow's landfall? Secondly, which physical processes are responsible for the typhoon convective/stratiform rainfall? What are the structures of convective and stratiform rainfall in terms of vertical velocity and cloud microphysical budget? To answer those questions, convective-stratiform rainfall separation is firstly conducted by using convective-stratiform rainfall separation method proposed by Li et al. (2014). Then the convective and stratiform rainfall clouds structures are analyzed in terms of vertical velocity, surface precipitation budget and cloud microphysical budget. The model configuration and methodology are briefly described in the next section. The 3D model simulations and the statistics results are presented in section 3. Finally, a summary is given.

\section{MODEL DESCRIPTION AND METHODOLOGY}

The data used in this study come from the 3D WRF model simulation of typhoon Fitow (2013), which is conducted in the framework of version 3.5.1 of the Weather Research and Forecasting Model (WRFV3.5.1). Three model domains with two-way nesting are used with horizontal grid resolutions of 27,9 , and $3 \mathrm{~km}$, respectively (Fig. 1). The coastal regions hit by Fitow in 2013 are covered by the innermost domain with grid resolution of $3 \mathrm{~km}$. All model domains have 35 vertical layers and the model top is $50 \mathrm{hPa}$. The physical schemes used in all model domains include shortwave (Dudhia 1989) and long wave (Mlawer et al. 1997) radiation parameterization schemes, 5-layer thermal diffusion land surface scheme (Dudhia 1996), Yonsei University (YSU) planetary boundary layer scheme (Hong and Pan 1996; Hong et al. 2006). No Cumulus scheme is used in all three model domains and microphysical parameterization scheme is used in all three domains. Liu et al. (2016) compared six cloud microphysics parameterization (MP) schemes: Purdue-Lin, Goddard scheme (Tao et al. 1989, 1993), WSM6 (Hong and Lim 2006), Morrison (Morrison et al. 2009), Thompson (Thompson et al. 2008), WDM6 (Lim and Hong 2010) in simulating typhoon Fitow (2013) in the WRF model, and found that the Purdue-Lin generally captured the typhoon rainfall intensities and areal coverage, which corresponds well with the observations, and it also 
showed certain advantages in the typhoon Fitow's rainfall simulations compared to the other microphysics schemes. Thus, the Purdue-Lin cloud microphysical parameterization scheme (Lin et al. 1983) is used in this study. The PurdueLin cloud microphysical scheme is a single-moment scheme that predicts mixing ratios of water vapor, cloud, raindrop, ice, snow and graupel. All its parameterization production terms are based on Lin et al. (1983) and Rutledge and Hobbs (1984) with modifications for saturation adjustment (following Tao et al. 1989) and ice sedimentation. The scheme is taken from the Purdue cloud model, and the details can be found in Chen and Sun (2002). The National Centers for Environmental Prediction (NCEP) global forecast system (GFS) final (FNL) operational global analysis data at $1^{\circ} \times$ $1^{\circ}$ horizontal resolution are used for the initial conditions and boundary conditions. Because severe disaster occurred during $6-8$ October 2013, the 36-hr simulation is initiated at 0000 UTC 6 October 2013, the output data is minute-data with the interval time of 1-hr. The first 12-hr simulation is treated as spin-up and the remaining 24-hr simulation data with the interval time of 1-hr in the innermost domain with the resolution of $3 \mathrm{~km}$ are used for the analysis of rainfall partitioning. Since the torrential 24-hr simulated rainfall generally distributed around the rectangular box in Fig. 1, the data over this box are used for rainfall separation.

Following Skamarock et al. (2008) and $\mathrm{Xu}$ and $\mathrm{Li}$ (2017), surface precipitation budget equation can be symbolically expressed as

$$
\mathrm{P}_{\mathrm{S}}=\mathrm{Q}_{\mathrm{WVT}}+\mathrm{Q}_{\mathrm{WVE}}+\mathrm{Q}_{\mathrm{WVF}}+\mathrm{Q}_{\mathrm{CM}}+\mathrm{Q}_{\mathrm{DIFV}}
$$

$\mathrm{Q}_{\mathrm{WVE}}=-\int_{1}^{0} \frac{1}{\mathrm{~g}}\left(\mathrm{~F}_{\mathrm{Q}_{\mathrm{v}, \mathrm{pbl}}}\right) \mathrm{d} \sigma$

$Q_{\text {wVT }}=-\int_{1}^{0} \frac{1}{g}\left(-\frac{\partial Q_{v}}{\partial t}\right) d \sigma$

$\mathrm{Q}_{\mathrm{WVF}}=-\int_{1}^{0} \frac{1}{\mathrm{~g}}\left\{-\nabla \cdot\left(\overrightarrow{\mathrm{V}} \mathrm{q}_{\mathrm{v}}\right)\right\} \mathrm{d} \sigma$

$\mathrm{Q}_{\mathrm{DIFV}}=-\int_{1}^{0} \frac{1}{\mathrm{~g}}\left(\mathrm{~F}_{\mathrm{Q}_{\mathrm{v}, \text { diff }}}\right) \mathrm{d} \sigma$

$$
\begin{aligned}
\mathrm{Q}_{\mathrm{CM}}= & -\int_{1}^{0} \frac{1}{\mathrm{~g}}\left[-\frac{\partial\left(\mathrm{Q}_{\mathrm{c}}+\sum_{\mathrm{x}} \mathrm{Q}_{\mathrm{x}}\right)}{\partial \mathrm{t}}-\nabla \cdot\left(\overrightarrow{\mathrm{V}} \mathrm{q}_{\mathrm{c}}+\overrightarrow{\mathrm{V}} \sum_{\mathrm{x}} \mathrm{q}_{\mathrm{x}}\right)\right] \mathrm{d} \sigma \\
& -\int_{1}^{0} \frac{1}{\mathrm{~g}}\left(\mathrm{~F}_{\mathrm{Q}_{\mathrm{c}, \text { pbl }}}+\mathrm{F}_{\mathrm{Q}_{\mathrm{i}, \text { bu }}}+\mathrm{F}_{\mathrm{Q}_{\mathrm{c}, \text { diff }}}\right) \mathrm{d} \sigma-\int_{1}^{0} \frac{1}{\mathrm{~g}} \sum_{\mathrm{x}}\left(\mathrm{F}_{\mathrm{Q}_{\mathrm{x}, \text { diff }}}\right) \mathrm{d} \sigma
\end{aligned}
$$

Here, $\mathrm{P}_{\mathrm{S}}$ is rain rate, $\mathrm{Q}_{\mathrm{CM}}$ is hydrometeor change/convergence. $\vec{V}$ is a three-dimensional wind vector, whereas it is a twodimensional vector in 2D cloud-resolving model. $Q_{v}=\mu_{d} q_{v}$,
$\mathrm{Q}_{\mathrm{c}}=\mu_{\mathrm{d}} \mathrm{q}_{\mathrm{c}}, \mathrm{Q}_{\mathrm{x}}=\mu_{\mathrm{d}} \mathrm{q}_{\mathrm{x}}[\mathrm{x}=(\mathrm{r}, \mathrm{i}, \mathrm{s}, \mathrm{g})]$, where $\mathrm{q}_{\mathrm{v}}, \mathrm{q}_{\mathrm{c}}, \mathrm{q}_{\mathrm{r}}, \mathrm{q}_{\mathrm{i}}, \mathrm{q}_{\mathrm{s}}$, $\mathrm{q}_{\mathrm{g}}$ denotes mixing ratio of water vapor, cloud, raindrop, ice, snow, and graupel, respectively, and $\mu_{\mathrm{d}}$ is the mass of dry air in the column. $\mathrm{V}_{\mathrm{Q}_{\mathrm{x}}}^{\mathrm{f}}[\mathrm{x}=(\mathrm{r}, \mathrm{i}, \mathrm{s}, \mathrm{g})]$ is the terminal velocity for raindrop, ice, snow, and graupel, respectively. $\mathrm{F}_{\mathrm{Q}_{v, p b}}$ represents the tendency of water vapor due to planetary boundary physical process, and $\mathrm{Q}_{\mathrm{wVE}}$ denotes evaporation of water vapor. $\mathrm{F}_{\mathrm{Q}_{\mathrm{c}, \mathrm{pbl}}}, \mathrm{F}_{\mathrm{Q}_{\mathrm{x}, \mathrm{ph}}}[\mathrm{x}=(\mathrm{r}, \mathrm{i}, \mathrm{s}, \mathrm{g})]$ denotes the tendency of cloud, raindrop, ice, snow, and graupel due to planetary boundary layer process, respectively. $\mathrm{F}_{\mathrm{Q}_{v, \text { diff }}}, \mathrm{F}_{\mathrm{Q}_{\mathrm{c} \text {, diff }}}, \mathrm{F}_{\mathrm{Q}_{\mathrm{x} \text {, diff }}}[\mathrm{x}=(\mathrm{r}, \mathrm{i}, \mathrm{s}, \mathrm{g})]$ denotes the diffusion tendency of water vapor, cloud water, raindrop, ice, snow, and graupel, respectively. The tendency terms could be output from the model simulations. The budget terms can be derived via mass integration $\left[-\int_{1}^{0} \frac{1}{\mathrm{~g}}(\cdot) \mathrm{d} \sigma\right]$, where $\mathrm{g}$ is the gravitational acceleration, $\sigma$ is the vertical coordinate, which varies from a value of 1 at the surface to 0 at the upper boundary of the model domain.

Surface rain rate $\left(\mathrm{P}_{\mathrm{S}}\right)$ is associated with water vapor convergence $\left(\mathrm{Q}_{\mathrm{WVF}}\right)$, local change of water vapor $\left(\mathrm{Q}_{\mathrm{WVT}}\right)$, hydrometeor change $\left(\mathrm{Q}_{\mathrm{CM}}\right)$, surface evaporation $\left(\mathrm{Q}_{\mathrm{wVE}}\right)$, and diffusion term $\left(\mathrm{Q}_{\mathrm{DIFV}}\right)$. Surface evaporation is always positive and diffusion term is negligibly small, while $\mathrm{Q}_{\mathrm{wvT}}$, $\mathrm{Q}_{\mathrm{WVF}}$, and $\mathrm{Q}_{\mathrm{CM}}$ can be negative or positive.

Cloud microphysical budget can be expressed as

$$
\begin{aligned}
\mathrm{S}_{\mathrm{qr}}= & \mathrm{P}_{\mathrm{SMLT}}\left(\mathrm{T}>\mathrm{T}_{0}\right)+\mathrm{P}_{\mathrm{SACW}}\left(\mathrm{T}>\mathrm{T}_{0}\right)+\mathrm{P}_{\mathrm{GACRPG}}\left(\mathrm{T}<\mathrm{T}_{0}\right) \\
& +\mathrm{P}_{\mathrm{GFR}}\left(\mathrm{T}<\mathrm{T}_{0}\right)+\mathrm{P}_{\mathrm{GACRG}}\left(\mathrm{T}<\mathrm{T}_{0}\right)+\mathrm{P}_{\mathrm{RAUT}} \\
& +\mathrm{P}_{\mathrm{SACR}}\left(\mathrm{T}<\mathrm{T}_{0}\right)+\mathrm{P}_{\mathrm{IACR}}\left(\mathrm{T}<\mathrm{T}_{0}\right)+\mathrm{P}_{\mathrm{GACW}}\left(\mathrm{T}>\mathrm{T}_{0}\right) \\
& +\mathrm{P}_{\mathrm{GMLT}}\left(\mathrm{T}>\mathrm{T}_{0}\right)+\mathrm{P}_{\mathrm{RACW}}+\mathrm{P}_{\mathrm{REVP}}
\end{aligned}
$$

Where $\mathrm{T}_{0}=0^{\circ} \mathrm{C} \cdot \mathrm{P}_{\mathrm{RACW}}$ is accretion of cloud water by rain, $\mathrm{P}_{\mathrm{GMLT}}$ is melting of graupel, $\mathrm{P}_{\mathrm{GACW}}$ is accretion of cloud water by graupel, $\mathrm{P}_{\mathrm{REVP}}$ is evaporation of raindrops, $\mathrm{S}_{\mathrm{qr}}$ is raindrop sources/sinks. Other rain microphysical processes have been listed in Table 1b. All those microphysical processes could be output from the WRF model. The other terms in the right hand of the Eq. (2) are negligibly small compared to $\mathrm{P}_{\mathrm{RACW}}, \mathrm{P}_{\mathrm{GMLT}}, \mathrm{P}_{\mathrm{REVP}}, \mathrm{P}_{\mathrm{GACW}}$, so rain microphysical budget can be approximately expressed as

$\mathrm{S}_{\mathrm{qr}} \approx \mathrm{P}_{\mathrm{RACW}}+\mathrm{P}_{\mathrm{GMLT}}+\mathrm{P}_{\mathrm{GACW}}+\mathrm{P}_{\mathrm{REVP}}$

To discuss why the contribution of condensation is significant in convective region compared to stratiform one, heat budget is analyzed. Following $\mathrm{Xu}$ et al. (2016), the heat budget can be written as

$\mathrm{F}_{\mathrm{loc}}=\mathrm{F}_{\mathrm{hd}}+\mathrm{F}_{\mathrm{rad}}+\mathrm{F}_{\mathrm{pbl}}+\mathrm{F}_{\mathrm{mp}}$

Equation (4) states that local heat change $\left(\mathrm{F}_{\text {loc }}\right)$ is determined by divergence of heat flux $\left(\mathrm{F}_{\mathrm{hd}}\right)$, radiation $\left(\mathrm{F}_{\mathrm{rad}}\right)$, sensible 
heat $\left(\mathrm{F}_{\mathrm{pbl}}\right)$, and release of latent heat $\left(\mathrm{F}_{\mathrm{mp}}\right)$. The heat budget can be derived via mass integration with $-\int_{1}^{0} \frac{1}{g}(\cdot) \mathrm{d} \sigma$.

The heat Eq. (4) is mass integrated, and the mass-integrated heat budget becomes

$\mathrm{S}_{\mathrm{HT}}=\mathrm{S}_{\mathrm{HF}}+\mathrm{S}_{\mathrm{RAD}}+\mathrm{S}_{\mathrm{HS}}+\mathrm{S}_{\mathrm{LH}}$

Where

$\mathrm{S}_{\mathrm{HT}}=-\int_{1}^{0} \frac{1}{\mathrm{~g}}\left(\mathrm{~F}_{\mathrm{loc}}\right) \mathrm{d} \sigma$

$\mathrm{S}_{\mathrm{HF}}=-\int_{1}^{0} \frac{1}{\mathrm{~g}}\left(\mathrm{~F}_{\mathrm{hd}}\right) \mathrm{d} \sigma$

$\mathrm{S}_{\mathrm{RAD}}=-\int_{1}^{0} \frac{1}{\mathrm{~g}}\left(\mathrm{~F}_{\mathrm{rad}}\right) \mathrm{d} \sigma$

$\mathrm{S}_{\mathrm{HS}}=-\int_{1}^{0} \frac{1}{\mathrm{~g}}\left(\mathrm{~F}_{\mathrm{pbl}}\right) \mathrm{d} \sigma$

$\mathrm{S}_{\mathrm{LH}}=-\int_{1}^{0} \frac{1}{\mathrm{~g}}\left(\mathrm{~F}_{\mathrm{mp}}\right) \mathrm{d} \sigma$

Here, $\mathrm{S}_{\mathrm{HT}}, \mathrm{S}_{\mathrm{HF}}, \mathrm{S}_{\mathrm{RAD}}, \mathrm{S}_{\mathrm{HS}}$, and $\mathrm{S}_{\mathrm{LH}}$ are local heat change, heat divergence, radiative heating, surface sensible heat, and latent heat, respectively. Negative values of $\mathrm{S}_{\mathrm{HF}}$ denotes cooling effects of heat divergence.

To investigate the structures of typhoon convectivestratiform rainfall, this study separated convective-strati- form rainfall in terms of vertical velocity and cloud microphysical processes using the partitioning method proposed by Li et al. (2014). Firstly, the surface rainfall is separated into eight rainfall types based on water vapor convergence/ divergence, local atmospheric moistening/drying, and hydrometeor change/convergence. The eight rain types are further combined into convective and stratiform rainfall types according to the vertical velocities and cloud microphysical budgets. The rain types associated with water vapor convergence form convective rainfall, where upward motions are prevailing and liquid microphysical processes are predominant in producing rainfall. Whereas the rain types with downward motions in the lower troposphere and dominant ice-phase microphysical processes form stratiform rainfall, the other rainfall types have more similar characteristics as stratiform rainfall in terms of vertical velocity and microphysical processes are also classified as stratiform rainfall.

\section{RESULTS}

The model simulation used in this study is similar to the control experiment in the previous study ( $\mathrm{Xu}$ et al. 2016), and the simulation has been verified with available observations (Xu and $\mathrm{Li}$ 2017). Xu et al. (2016) and $\mathrm{Xu}$ and $\mathrm{Li}$ (2017) verified the 24-hr accumulated rainfall with observations, and it showed that the simulations of 24-hr accumulated rainfall features have been reproduced well. More detailed verification of the simulation could refer to the study by $\mathrm{Xu}$ and $\mathrm{Li}$ (2017).

Following Shen et al. (2010), rain rate at each grid can be classified into one of the eight rainfall types (Table 1). In the eight types of rainfall, T, F, and M denote local atmospheric

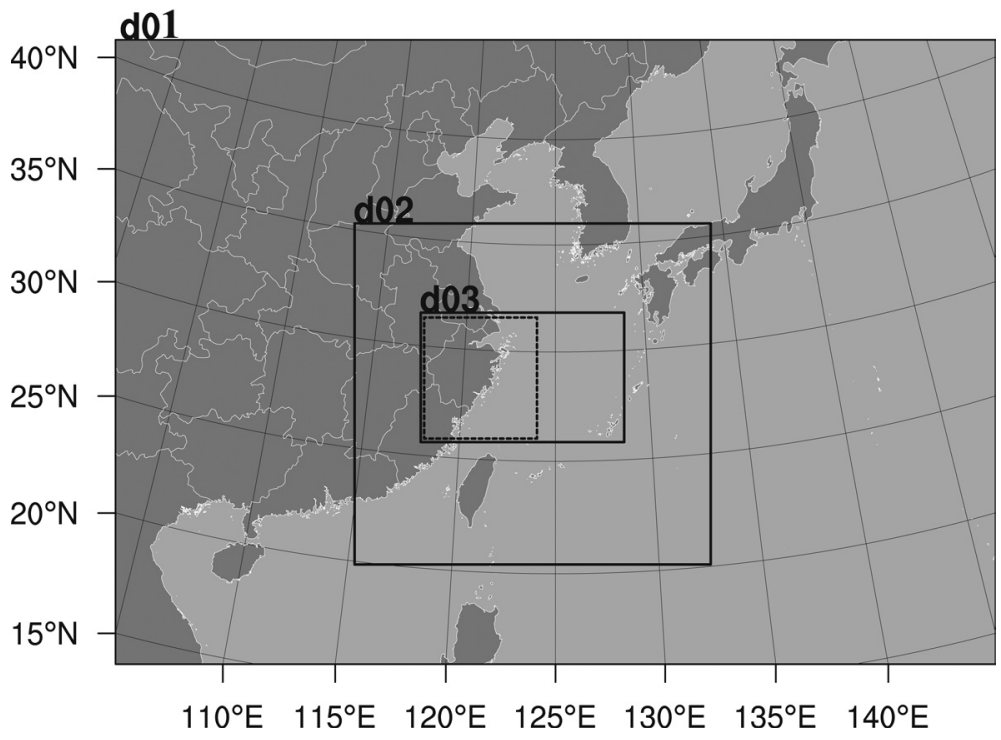

Fig. 1. Map of model domains for d01 with the grid mesh of $27 \mathrm{~km}$, d02 with grid mesh of $9 \mathrm{~km}$, and d03 with grid mesh of $3 \mathrm{~km}$. The dashed lines denote the box of $208 \times 200$ grid points in south-north and west-east contained within the innermost 3-km domain (generally the rectangular box of $26-31.5^{\circ} \mathrm{N}, 118-124^{\circ} \mathrm{E}$ ). 
Table 1. Summary of (a) rain types and (b) microphysical processes and the parameterization scheme used in the simulation is Lin et al. 1983 (Lin83).

(a)

\begin{tabular}{cl}
\hline Type & Description \\
\hline TFM & Local atmospheric drying $\left(\mathrm{Q}_{\mathrm{wvt}}>0\right)$, water vapor convergence $\left(\mathrm{Q}_{\mathrm{wvf}}>0\right)$, and hydrometeor loss/convergence $\left(\mathrm{Q}_{\mathrm{cm}}>0\right)$ \\
TFm & Local atmospheric drying $\left(\mathrm{Q}_{\mathrm{wvt}}>0\right)$, water vapor convergence $\left(\mathrm{Q}_{\mathrm{wvf}}>0\right)$, and hydrometeor gain/divergence $\left(\mathrm{Q}_{\mathrm{cm}}<0\right)$ \\
tFM & Local atmospheric moistening $\left(\mathrm{Q}_{\mathrm{wvt}}<0\right)$, water vapor convergence $\left(\mathrm{Q}_{\mathrm{wvf}}>0\right)$, and hydrometeor loss $/$ convergence $\left(\mathrm{Q}_{\mathrm{cm}}>0\right)$ \\
tFm & Local atmospheric moistening $\left(\mathrm{Q}_{\mathrm{wvt}}<0\right)$, water vapor convergence $\left(\mathrm{Q}_{\mathrm{wvf}}>0\right)$, and hydrometeor gain/divergence $\left(\mathrm{Q}_{\mathrm{cm}}<0\right)$ \\
TfM & Local atmospheric drying $\left(\mathrm{Q}_{\mathrm{wvt}}>0\right)$, water vapor divergence $\left(\mathrm{Q}_{\mathrm{wvf}}<0\right)$, and hydrometeor loss/convergence $\left(\mathrm{Q}_{\mathrm{cm}}>0\right)$ \\
Tfm & Local atmospheric drying $\left(\mathrm{Q}_{\mathrm{wvt}}>0\right)$, water vapor divergence $\left(\mathrm{Q}_{\mathrm{wvf}}<0\right)$, and hydrometeor gain/divergence $\left(\mathrm{Q}_{\mathrm{cm}}<0\right)$ \\
tfM & Local atmospheric moistening $\left(\mathrm{Q}_{\mathrm{wvt}}<0\right)$, water vapor divergence $\left(\mathrm{Q}_{\mathrm{wvf}}<0\right)$, and hydrometeor loss $/$ convergence $\left(\mathrm{Q}_{\mathrm{cm}}>0\right)$ \\
tfm & Local atmospheric moistening $\left(\mathrm{Q}_{\mathrm{wvt}}<0\right)$, water vapor divergence $\left(\mathrm{Q}_{\mathrm{wvf}}<0\right)$, and hydrometeor gain/divergence $\left(\mathrm{Q}_{\mathrm{cm}}<0\right)$ \\
\hline
\end{tabular}

(b)

\begin{tabular}{|c|c|c|}
\hline Notation & Description & Scheme \\
\hline $\mathrm{P}_{\mathrm{REVP}}$ & Evaporation of raindrops & Lin83 \\
\hline $\mathrm{P}_{\text {SMLT }}$ & Growth of raindrops by melting of snow & $\operatorname{Lin} 83$ \\
\hline $\mathrm{P}_{\mathrm{SACW}}$ & Growth of snow by the accretion of cloud water & Lin83 \\
\hline $\mathrm{P}_{\mathrm{GACRP}}$ & Growth of graupel by the accretion of raindrops in dry processes & $\operatorname{Lin} 83$ \\
\hline $\mathrm{P}_{\mathrm{GFR}}$ & Growth of graupel by freezing of raindrops & $\operatorname{Lin} 83$ \\
\hline $\mathrm{P}_{\mathrm{GACR}}$ & Growth of graupel by the accretion of raindrops in wet processes & Lin83 \\
\hline $\mathrm{P}_{\text {RAUT }}$ & Growth of raindrops by the auto conversion of cloud water & $\operatorname{Lin} 83$ \\
\hline $\mathrm{P}_{\mathrm{SACR}}$ & Growth of snow by the accretion of rain & $\operatorname{Lin} 83$ \\
\hline $\mathrm{P}_{\mathrm{IACR}}$ & Growth of cloud ice by the accretion of raindrops & $\operatorname{Lin} 83$ \\
\hline $\mathrm{S}_{\mathrm{qv}}$ & Source and sinks for water vapor & Lin83 \\
\hline $\mathrm{S}_{\mathrm{qr}}$ & Source and sinks for raindrops & Lin83 \\
\hline $\mathrm{S}_{\mathrm{qc}}$ & Source and sinks for cloud & Lin83 \\
\hline $\mathrm{S}_{\mathrm{qi}}$ & Source and sinks for ice & Lin83 \\
\hline $\mathrm{S}_{\mathrm{qs}}$ & Source and sinks for snow & Lin83 \\
\hline $\mathrm{S}_{\mathrm{qg}}$ & Source and sinks for graupel & Lin83 \\
\hline $\mathrm{P}_{\mathrm{GACW}}$ & Growth of graupel by the accretion of cloud water & Lin83 \\
\hline $\mathrm{P}_{\mathrm{GMLT}}$ & Growth of raindrops by melting of graupel & Lin83 \\
\hline $\mathrm{P}_{\mathrm{RACW}}$ & Growth of raindrops by the accretion of cloud water & Lin83 \\
\hline$P_{\text {LADJ }}$ & Saturation adjustment of cloud water ( growth of cloud ice by the condensation of supersaturated vapor) & Lin83 \\
\hline $\mathrm{P}_{\text {IADJ }}$ & Saturation adjustment of cloud ice ( $\sim$ growth of cloud ice by the deposition of supersaturated vapor) & Lin83 \\
\hline $\mathrm{P}_{\mathrm{SFI}}$ & Transfer of cloud ice to form snow (growth of snow by the riming of cloud ice) & Lin83 \\
\hline $\mathrm{P}_{\mathrm{SDEP}}$ & Growth of snow by the deposition of vapor & $\operatorname{Lin} 83$ \\
\hline $\mathrm{P}_{\mathrm{GACS}}$ & Growth of graupel by the accretion of snow & Lin83 \\
\hline $\mathrm{P}_{\mathrm{GSUB}}$ & Growth of water vapor by the sublimation of graupel & Lin83 \\
\hline $\mathrm{P}_{\mathrm{GDEP}}$ & Growth of graupel by the deposition of vapor & Lin83 \\
\hline $\mathrm{P}_{\mathrm{GMLTEVP}}$ & Growth of water vapor by the evaporation of melting graupel & Lin83 \\
\hline $\mathrm{P}_{\mathrm{SSUB}}$ & Growth of water vapor by the sublimation of snow & Lin83 \\
\hline
\end{tabular}


drying $\left(\mathrm{Q}_{\mathrm{WVT}}>0\right)$, water vapor convergence $\left(\mathrm{Q}_{\mathrm{WVF}}>0\right)$, and hydrometeor loss and convergence $\left(\mathrm{Q}_{\mathrm{CM}}>0\right)$, respectively; $\mathrm{t}, \mathrm{f}$, and $\mathrm{m}$ denote local atmospheric moistening $\left(\mathrm{Q}_{\mathrm{wvT}}<0\right)$, water vapor divergence $\left(\mathrm{Q}_{\mathrm{WVF}}<0\right)$, and hydrometeor gain and divergence $\left(\mathrm{Q}_{\mathrm{CM}}<0\right)$, respectively. Using the grid-scale rain rate and variables to Eq. (1), rain rate at each grid can be classified into one of the eight rain types (Table 1). Based on the classification results, the vertical velocity and cloud microphysical terms in Eq. (2) and heat budget terms in Eq. (4) at each grid can be classified into one of the eight rain types as the rain type in the grid, the contoured frequency by altitude diagrams (CFAD) of vertical velocity for the eight types of rainfall can be calculated as well. For example, if the rain rate at a grid is classified as "TFM", then the vertical velocity at the same grid is classified as "TFM". Since tfm is negligibly small, thus it is excluded in the following discussions. Note that the simulated vertical velocity with the interval time of $1-\mathrm{hr}$ on the total 35 vertical layers output from the innermost domain with the horizontal resolution of $3 \mathrm{~km}$ during the periods from 1200 UTC 6 October to 1200 UTC 7 October 2013 are used to compute CFAD and profiles of vertical velocity. Surface rainfall budget, cloud microphysical budget, and heat budget are calculated based on the Eqs. (1) - (5) with the hourly variables output from the simulations for the 24-hr integrations during the periods from 1200 UTC 6 October to 1200 UTC 7 October 2013.

Three rain types (tFm, TFm, and TFM) associated with water vapor convergence have upward motions in the entire troposphere (Fig. 2a). Additionally, they have maximum upward motions in the lower troposphere around 3.5, 3.5, and $4.5 \mathrm{~km}$, respectively, which increases liquid hydrometeors (Fig. 2a). The analysis of rain microphysical budget shows that $\mathrm{P}_{\mathrm{RACW}}$ is 2 - 3 times larger than $\mathrm{P}_{\mathrm{GMLT}}+\mathrm{P}_{\mathrm{GACW}}$ in
TFM, tFm, and TFm (Table 2a), indicating water hydrometeor processes are dominant.

Two rain types (TfM and tfM) associated with water vapor divergence have downward motions below $6 \mathrm{~km}$ and upward motions above $6 \mathrm{~km}$ (Fig. 2a). In those two rain types, $\mathrm{P}_{\mathrm{GMLT}}+\mathrm{P}_{\mathrm{GACW}}$ is about twice larger than $\mathrm{P}_{\mathrm{RACW}}$ (Table 2a). Although it has water vapor convergence, tFM shows downward motions below $4 \mathrm{~km}$ and upward motions above $4 \mathrm{~km}$. The maximum upward and downward vertical velocities are $2.5 \mathrm{~cm} \mathrm{~s}^{-1}$ at $8 \mathrm{~km}$ and $-1 \mathrm{~cm} \mathrm{~s}^{-1}$ near the surface (Fig. 2a). The upward motions of tFM in the mid- and upper troposphere lead to a larger $\mathrm{P}_{\mathrm{GMLT}}+\mathrm{P}_{\mathrm{GACW}}$, compared to $\mathrm{P}_{\mathrm{RACW}}$. Tfm shows weak upward motions throughout the troposphere (Fig. 2a), and $\mathrm{P}_{\mathrm{GMLT}}+\mathrm{P}_{\mathrm{GACW}}$ is slightly larger than $\mathrm{P}_{\mathrm{RACW}}$.

The contoured frequency by altitude diagrams (CFAD) of vertical velocity for the seven types of rainfall are shown in Fig. 3. TFM, TFm, and tFm have broader distributions of vertical velocity than other rain types do. The maximum vertical velocity is larger than $10 \mathrm{~m} \mathrm{~s}^{-1}$ in TFM, TFm, and tFm (Figs. 3a, b, d) and less than $7 \mathrm{~m} \mathrm{~s}^{-1}$ in other rain types. In addition, their vertical velocities are asymmetrically distributed with broader distributions of upward motions. The maximum upward motion is up to $14 \mathrm{~m} \mathrm{~s}^{-1}$ (Figs. 3a, b, d), whereas the maximum downward motion is confined within $-5 \mathrm{~m} \mathrm{~s}^{-1}$, indicating upward motions are prevailing in TFM, $\mathrm{TFm}$, and tFm. In contrast, TfM and tfM show much narrower distributions of vertical velocity than other rain types do. Their vertical velocities are asymmetrically distributed with broader distributions of downward motions up to $-6 \mathrm{~m} \mathrm{~s}^{-1}$ in the mid and lower troposphere and that of upward motions around $5 \mathrm{~m} \mathrm{~s}^{-1}$ in the upper troposphere (Figs. 3e, g). In tFM, the distribution of downward motion is broader (narrower) than that of upward motion in the lower (upper) troposphere
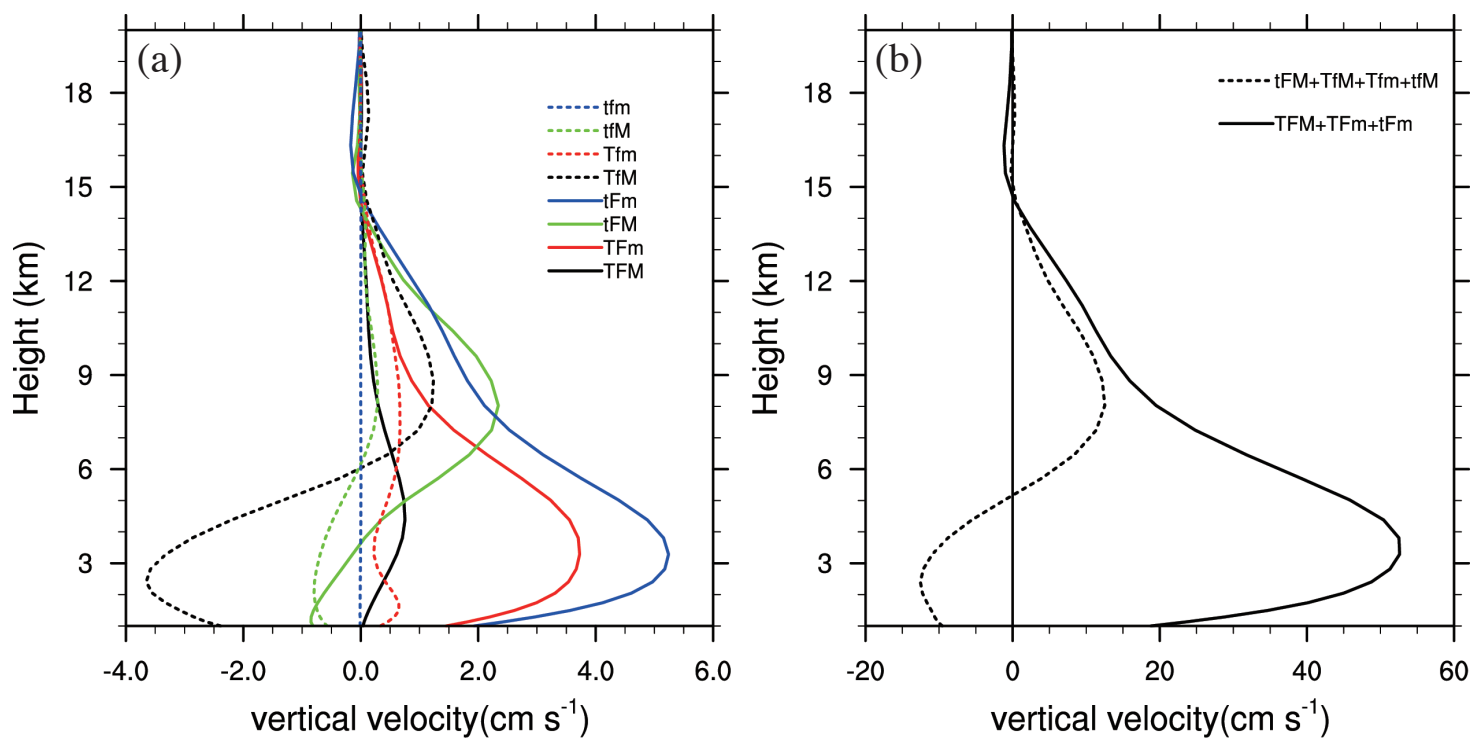

Fig. 2. Vertical profiles of mean vertical velocity $\left(\mathrm{cm} \mathrm{s}^{-1}\right)$ for (a) rain types TFM (black solid), TFm (red solid), tFM (green solid), tFm (blue solid), TfM (black dashed), Tfm (red dashed), and tfM (green dashed), and (b) TFM + TFm + tFm (solid) and tFM + TfM + Tfm + tfM (dashed). 
Table 2. (a) Cloud microphysical budget $\left(\mathrm{mm} \mathrm{h}^{-1}\right)$ and fraction coverage (FC; \%) for seven rain types, Sqr is rainfall source/sink, (b) rain intensity $\left(\mathrm{RI}=\mathrm{P}_{\mathrm{S}} / \mathrm{FC} \times\right.$ $100 \%)$ and contribution of surface precipitation budget $\left(\mathrm{P}_{\mathrm{S}}, \mathrm{Q}_{\mathrm{WVT}}, \mathrm{Q}_{\mathrm{WVF}}, \mathrm{Q}_{\mathrm{WVE}}\right.$, $\mathrm{Q}_{\mathrm{CM}}$, and $\left.\mathrm{Q}_{\mathrm{DIFV}}\right)$ from seven rain types, and fractional coverage (FC), rain intensity (RI), and (c) contribution of surface precipitation budget terms $\left(\mathrm{P}_{\mathrm{S}}, \mathrm{Q}_{\mathrm{wvT}}\right.$, $\mathrm{Q}_{\mathrm{WVF}}, \mathrm{Q}_{\mathrm{WVE}}, \mathrm{Q}_{\mathrm{CM}}$, and $\left.\mathrm{Q}_{\mathrm{DIFV}}\right)$ from TFM + TFm + tFm and tFM + Tfm + TfM + tfM, (d) Rain microphysical budget for convective and stratiform rainfall. Units are $\mathrm{mm} \mathrm{h}^{-1}$ for budgets and RI, and \% for FC.

(a)

\begin{tabular}{c|ccccccc}
\hline & TFM & TFm & tFM & tFm & TfM & Tfm & tfM \\
\hline $\mathrm{S}_{\text {qr }}$ & 0.24 & 0.80 & 0.49 & 0.94 & 0.40 & 0.14 & 0.05 \\
$\mathrm{P}_{\text {RACW }}$ & 0.16 & 0.61 & 0.25 & 0.69 & 0.20 & 0.08 & 0.03 \\
$\mathrm{P}_{\text {GMLT }}$ & 0.08 & 0.17 & 0.38 & 0.26 & 0.35 & 0.08 & 0.05 \\
$\mathrm{P}_{\text {REVP }}$ & -0.02 & -0.03 & -0.16 & -0.07 & -0.17 & -0.04 & -0.02 \\
$\mathrm{P}_{\text {GACW }}$ & 0.02 & 0.06 & 0.04 & 0.07 & 0.03 & 0.01 & 0.00 \\
$\mathrm{FC}$ & 1.11 & 5.20 & 12.68 & 11.91 & 15.61 & 5.51 & 2.17 \\
\hline
\end{tabular}

(b)

\begin{tabular}{c|ccccccc}
\hline & TFM & TFm & tFM & tFm & TfM & Tfm & tfM \\
\hline $\mathrm{P}_{\mathrm{S}}$ & 0.33 & 0.43 & 0.73 & 0.48 & 0.76 & 0.09 & 0.08 \\
$\mathrm{Q}_{\text {WVT }}$ & 0.07 & 0.36 & -1.87 & -1.61 & 2.52 & 0.88 & -0.05 \\
$\mathrm{Q}_{\text {WVF }}$ & 0.14 & 0.88 & 1.90 & 3.10 & -2.80 & -0.61 & -0.07 \\
$\mathrm{Q}_{\text {WVE }}$ & 0.00 & 0.01 & 0.02 & 0.02 & 0.02 & 0.01 & 0.00 \\
$\mathrm{Q}_{\mathrm{CM}}$ & 0.12 & -0.79 & 0.66 & -1.00 & 1.00 & -0.19 & 0.18 \\
$\mathrm{Q}_{\text {DIFV }}$ & -0.01 & -0.03 & 0.02 & -0.03 & 0.02 & 0.00 & 0.01 \\
$\mathrm{RI}$ & 29.89 & 8.35 & 5.75 & 4.02 & 4.85 & 1.61 & 3.51 \\
\hline
\end{tabular}

(c)

\begin{tabular}{c|cc}
\hline & TFM + TFm + tFm & tFM + Tfm + TfM + tfM \\
\hline $\mathrm{P}_{\mathrm{s}}$ & 1.25 & 1.65 \\
$\mathrm{Q}_{\mathrm{WVT}}$ & -1.18 & 1.47 \\
$\mathrm{Q}_{\mathrm{WVF}}$ & 4.13 & -1.58 \\
$\mathrm{Q}_{\mathrm{WVE}}$ & 0.03 & 0.05 \\
$\mathrm{Q}_{\mathrm{CM}}$ & -1.66 & 1.66 \\
$\mathrm{Q}_{\mathrm{DIFV}}$ & -0.06 & 0.05 \\
$\mathrm{FC}$ & 18.22 & 35.97 \\
$\mathrm{RI}$ & 6.94 & 4.58 \\
\hline
\end{tabular}

(d)

\begin{tabular}{c|cc}
\hline & TFM + TFm + tFm & tFM + Tfm + TfM + tfM \\
\hline $\mathrm{S}_{\mathrm{qr}}$ & 1.97 & 1.09 \\
$\mathrm{P}_{\mathrm{RACW}}$ & 1.45 & 0.56 \\
$\mathrm{P}_{\mathrm{GMLT}}$ & 0.51 & 0.86 \\
$\mathrm{P}_{\mathrm{REVP}}$ & -0.12 & -0.39 \\
$\mathrm{P}_{\mathrm{GACW}}$ & 0.15 & 0.08 \\
\hline
\end{tabular}



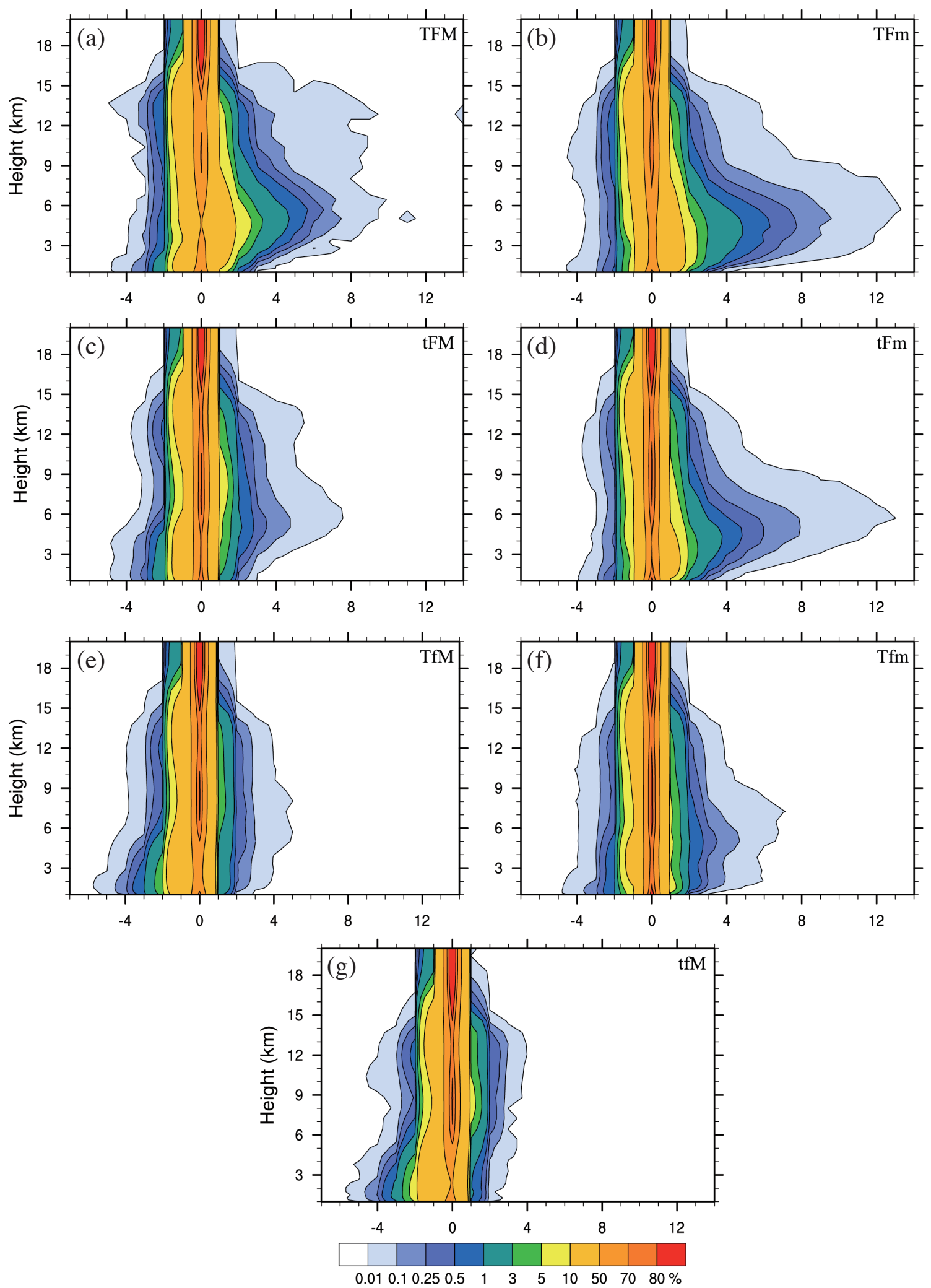

Fig. 3. CFAD of vertical velocity ( $\mathrm{m} \mathrm{s}^{-1}$ ) for (a) TFM, (b) TFm, (c) tFM, (d) tFm, (e) TfM, (f) Tfm, (g) tfM. The simulated vertical velocitied on the 35 vertical levels are used to conduct probability ditribution, those levels generally correponding to the 35 vertical sigma levels in the WRF model, and the bin size is $1 \mathrm{~m} \mathrm{~s}^{-1}$. Contour intervals are $0.01,0.1,0.25,0.5,1,3,5,10,50,70$, and $80 \%$, respectively. 
(Fig. 3c), leading to mean downward motions in the lower troposphere and upward motions in the upper troposphere as shown in Fig. 2a. In Tfm, both upward motion and downward motion are prevailing in the entire troposphere (Fig. 3f). For those velocities with frequency of more than $10 \%$, downward motions are broader distributed than upward motions around 2 - $5 \mathrm{~km}$, indicating downward motions are dominant in the mid- and lower troposphere for the rain type Tfm.

The analysis of microphysical budget and vertical velocity profiles and CFAD of vertical velocity suggests that TFM, TFm, and tFm can be categorized into convective rainfall, while TfM and tfM can be categorized into stratiform rainfall. Meanwhile, tFM and Tfm can be put into the mixed category that may be considered as a transition phase from the convective rainfall to stratiform rainfall (Sui et al.2007; Li et al. 2014). Rain type of tFM shows downward motions in the lower troposphere (Fig. 2a), and ice microphysical processes are more important than liquid microphysical processes (Table 2a), indicating similar characteristics as stratiform rainfall. Tfm has water vapor divergence, and ice microphysical process is slightly more important than liquid microphysical process (Tables $2 \mathrm{a}, \mathrm{b}$ ). The rain intensity and upward motion in Tfm are much weaker than those in TFM, TFm, and tFm. This indicates Tfm has more similar characteristics as stratiform rainfall. It may be more reasonable to categorize tFM and Tfm into the stratiform rainfall, since $\mathrm{tFM}$ and $\mathrm{Tfm}$ show more similar characteristics as the stratiform rainfall. Therefore, $\mathrm{TFM}+\mathrm{TFm}+\mathrm{tFm}$ and $\mathrm{TfM}$ $+\mathrm{tfM}+\mathrm{tFM}+\mathrm{Tfm}$ are respectively categorized as convective and stratiform rainfall.

We first analyze the convective and stratiform rainfall structures by examining statistics of vertical velocity. In the convective regions $(\mathrm{TFM}+\mathrm{TFm}+\mathrm{tFm})$, mean vertical motion is upward throughout the troposphere with the maximum velocity of $52 \mathrm{~cm} \mathrm{~s}^{-1}$ around $3.5 \mathrm{~km}$ (Fig. 2b). Figure 4a shows a broader distribution of upward motion than that of downward motion, and the maximum upward motion could reach to $13 \mathrm{~m} \mathrm{~s}^{-1}$. In the stratiform regions (TfM $+\mathrm{tfM}+\mathrm{tFM}+\mathrm{Tfm})$, the mean vertical motion is downward in the mid- and lower troposphere with its maximum of $-13 \mathrm{~cm} \mathrm{~s}^{-1}$ around $2.5 \mathrm{~km}$, whereas the mean vertical motion is upward in the upper troposphere with its maximum of $13 \mathrm{~cm} \mathrm{~s}^{-1}$ around $8 \mathrm{~km}$ (Fig. 2b). Figure 4b shows a broader distribution of downward motion than that of upward motion in the lower troposphere with the maximum downward motion of $-5 \mathrm{~m} \mathrm{~s}^{-1}$, while it shows a broader distribution of upward motion in the upper troposphere with frequency of more than $5 \%$ and maximum upward motion reach to $7 \mathrm{~m} \mathrm{~s}^{-1}$ around $6 \mathrm{~km}$.

We further analyze the convective and stratiform rainfall structures by examining surface precipitation budget and cloud microphysical budget for each rain type (Tables 2c, d). Over convective rainfall region (TFM + TFm $+\mathrm{tFm}), \mathrm{TFM}+\mathrm{TFm}+\mathrm{tFm}$ is connected with water vapor convergence, hydrometeor divergence, and local atmospheric moistening in the $3 \mathrm{D}$ model. Among the three rain types (TFM, TFm, tFm), TFM possesses the maximum rainfall intensity $\left(29.89 \mathrm{~mm} \mathrm{~h}^{-1}\right)$. Both water vapor convergence and hydrometeor convergence contribute about $40 \%$ to the total rain rate, indicating the importance of hydrometeor convergence for producing the maximum rainfall, though convective rainfall is generally associated with hydrometeor divergence. As the other two components of convective rainfall, TFm and tFm show large hydrometeor divergence. In TFm, the hydrometeor gain (divergence) is largely offset by the water vapor convergence, and rain rate is mainly associated with the local atmospheric drying. The rainfall intensity of TFm is much smaller than that of TFM. If the cloud hydrometeor transport is eliminated in TFm and TFM, the rain intensity of TFM $\left(21 \mathrm{~mm} \mathrm{~h}^{-1}\right)$ would be smaller than that of TFm $\left(24.8 \mathrm{~mm} \mathrm{~h}^{-1}\right)$, which again indicates the importance of cloud hydrometeor convergence in determining the maximum

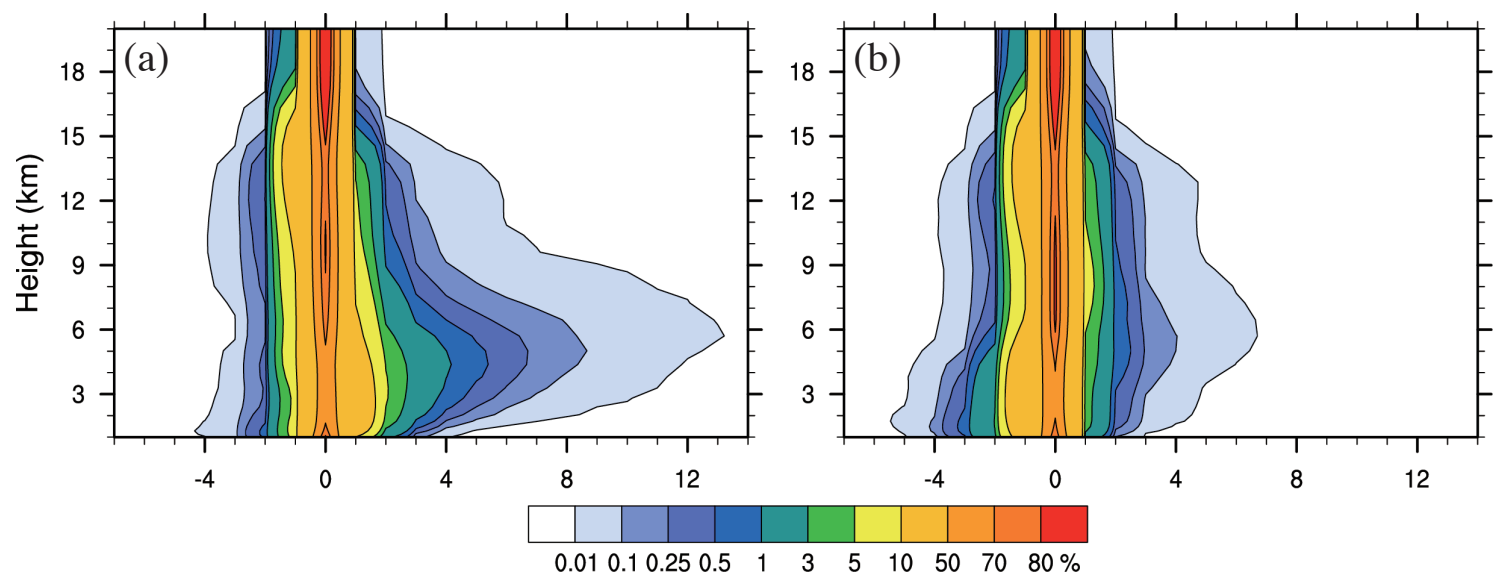

Fig. 4. CFAD of vertical velocity $\left(\mathrm{m} \mathrm{s}^{-1}\right)$ for the (a) convective (TFM $\left.+\mathrm{TFm}+\mathrm{tFm}\right)$ and (b) stratiform (tFM $\left.+\mathrm{Tfm}+\mathrm{TfM}+\mathrm{tfM}\right)$ rainfall. The simulated vertical velocitied on the 35 vertical levels are used to conduct probability ditribution, those levels generally correponding to the 35 vertical sigma levels in the WRF model, and the bin size is $1 \mathrm{~m} \mathrm{~s}^{-1}$. Contour intervals are $0.01,0.1,0.25,0.5,1,3,5,10,50,70$, and $80 \%$, respectively. 
rainfall as indicated by $\mathrm{Xu}$ et al. (2017). In tFm, the water vapor convergence is used to moisten the local atmosphere and to support the cloud hydrometeor divergence. Over stratiform rainfall region ( $\mathrm{tFM}+\mathrm{TfM}+\mathrm{Tfm}+\mathrm{tfM})$, surface precipitation budget equation shows that precipitation is primarily connected with hydrometeor convergence, and local atmospheric drying, whereas water vapor divergence is a negative contributor (Table 2c). The local atmospheric drying mainly occurs in TfM among the four types (Table $2 b$ ), whereas the cloud hydrometeor convergence mainly appears in TfM and tFM. As a result, TfM and tFM contribute about $90 \%$ to stratiform rainfall. Figure 5 shows that the stratiform rainfall budget $\left(1.65 \mathrm{~mm} \mathrm{~h}^{-1}\right)$ is larger than the convective rainfall budget $\left(1.25 \mathrm{~mm} \mathrm{~h}^{-1}\right)$, since the fractional coverage of stratiform rainfall (35.97\%) is much larger than that of convective rainfall $(18.22 \%)$. Table $2 \mathrm{c}$ shows that the rain intensity of convective rainfall $\left(6.94 \mathrm{~mm} \mathrm{~h}^{-1}\right)$ is much more intense than that of stratiform rainfall $\left(4.58 \mathrm{~mm} \mathrm{~h}^{-1}\right)$.

The time-mean cloud microphysics budgets averaged over the dashed domain in Fig. 1 are calculated in the
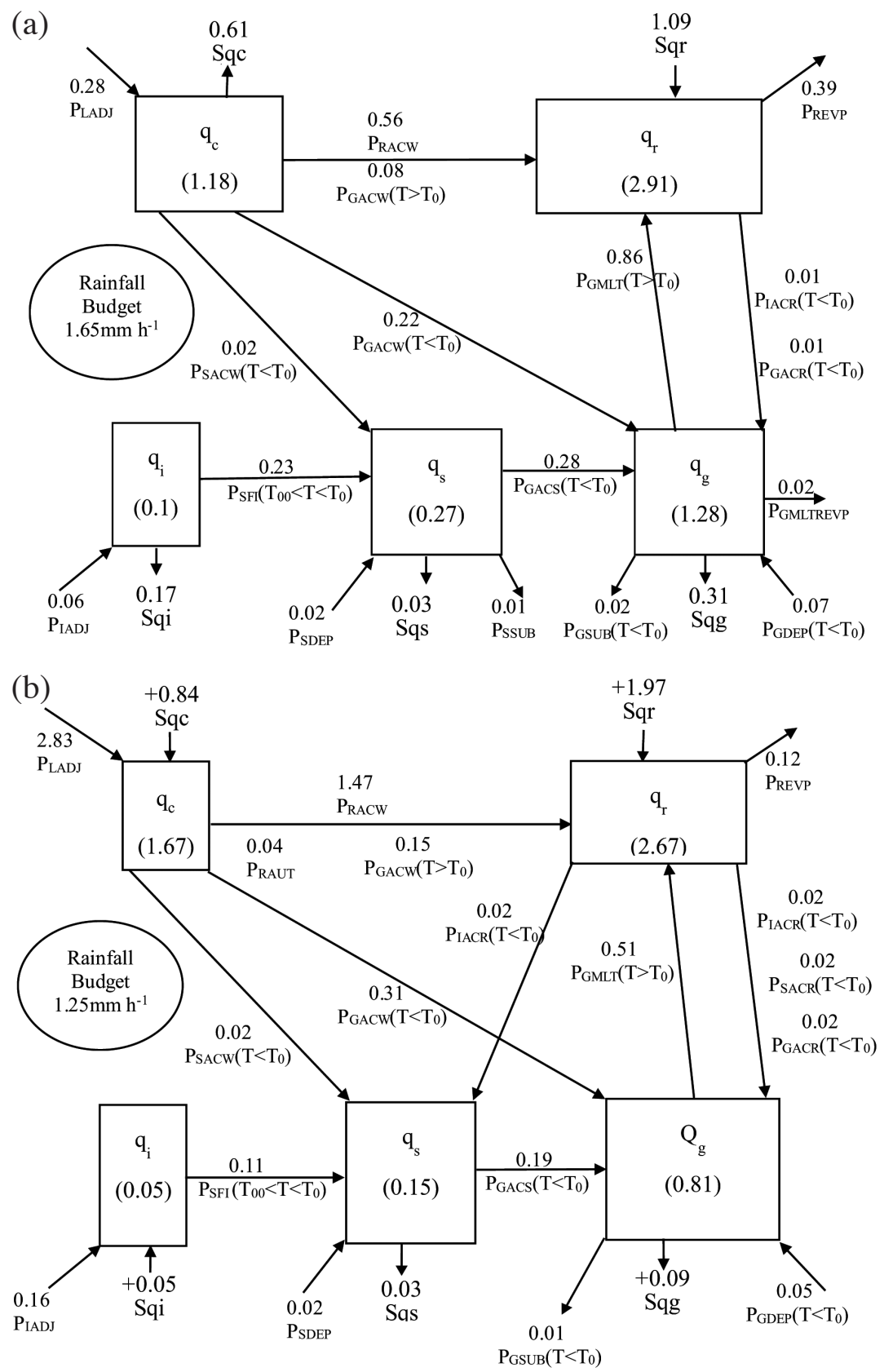

Fig. 5. Cloud microphysical budgets averaged over the (a) stratiform, (b) convective rainfall regions, partitioned by the method in this study. $\mathrm{T}_{0}=$ $0^{\circ} \mathrm{C}, \mathrm{T}_{00}=-31^{\circ} \mathrm{C}$. Units for cloud hydrometeors and conversions are $\mathrm{mm}$ and $\mathrm{mm} \mathrm{h}^{-1}$, respectively. The value in the parenthesis of the rectangular box indicates the content of vertically integrated mixing ratios of the specific hydrometeors (cloud, raindrop, cloud ice, snow, and graupel). 
stratiform and convective rainfall regions in Fig. 5. The cloud microphysical terms of Purdue-Lin microphysical parameterization scheme in WRF model are listed in Table $1 \mathrm{~b}$. $\mathrm{P}_{\mathrm{RAUT}}$ was negligibly small in stratiform rainfall regions (less than $0.01 \mathrm{~mm} \mathrm{~h}^{-1}$ ), thus it was excluded in Fig. 5a. $P_{\text {SMLT }}$ was negligibly small both in stratiform and convective rainfall regions (less than $0.01 \mathrm{~mm} \mathrm{~h}^{-1}$ ), thus it was excluded in the Fig. 5. In the stratiform region, the melting of graupel $\left(\mathrm{P}_{\mathrm{GMLT}}\right.$ $\left.=0.86 \mathrm{~mm} \mathrm{~h}^{-1}\right)$ and accretion of cloud water by rain $\left(\mathrm{P}_{\mathrm{RACW}}\right.$ $\left.=0.56 \mathrm{~mm} \mathrm{~h}^{-1}\right)$ cancel out the raindrop evaporation $\left(\mathrm{P}_{\mathrm{REVP}}\right.$ $\left.=0.39 \mathrm{~mm} \mathrm{~h}^{-1}\right)$, contributing to the rain source $(\mathrm{Sqr}=1.09$ $\mathrm{mm} \mathrm{h}^{-1}$ ). Among those microphysical processes, the melting of graupel is dominant in producing rainfall. Another difference between the two regions is that the condensation $\left(\mathrm{P}_{\mathrm{LADJ}}\right)$ in convective region is much larger than that in the stratiform region, and heat budget is analyzed to explain the difference. In the convective region, heat divergence $\left(\mathrm{S}_{\mathrm{HF}}\right.$ $=-8.32)$ is much stronger in convective regions than that $\left(\mathrm{S}_{\mathrm{HF}}=0.43\right)$ in stratiform rainfall regions, leading to much stronger cooling, thus the contribution of condensation was quite significant $\left(2.83 \mathrm{~mm} \mathrm{~h}^{-1}\right)$ compared to stratiform one $\left(0.28 \mathrm{~mm} \mathrm{~h}^{-1}\right)$, indicated by more latent heat $\left(\mathrm{S}_{\mathrm{LH}}=8.51\right)$ in stratiform region that that in convective region $\left(\mathrm{S}_{\mathrm{LH}}=-0.23\right)$. The large quantity of vapor condensation in the convective region cause a large accretion of cloud water by raindrops $\left(\mathrm{P}_{\mathrm{RACW}}=1.47 \mathrm{~mm} \mathrm{~h}^{-1}\right)$. The accretion of cloud water by raindrop is the main source for the rain development, albeit the melting of graupel $\left(\mathrm{P}_{\mathrm{GMLT}}=0.51 \mathrm{~mm} \mathrm{~h}^{-1}\right)$ and accretion of cloud water by graupel $\left(\mathrm{P}_{\mathrm{GACW}}=0.15 \mathrm{~mm} \mathrm{~h}^{-1}\right)$ also contribute to the growth of rainfall. This indicates water hydrometeors are dominant in producing convective rainfall.

Finally, The distribution of the seven types of rain is shown in Fig. 6a at 1100 UTC 6 October 2013, when 1-hr rain rate averaged over the box of $26-31.5^{\circ} \mathrm{N}, 118-124^{\circ} \mathrm{E}$ reaches its maximum. Figures $6 \mathrm{a}-\mathrm{e}$ show each type of rain plays an important role in producing rainfall. Horizontal distribution of convective and stratiform rainfall in Figs. 6f - j shows the typhoon convective-stratiform rainfall structures. The narrow convective rainfall regions are surrounded by broad stratiform rainfall regions. Regardless of isolated convections in the eyewall and spiral rainbands, the evolution of distributions of convective rainfall shows interesting pictures. At 1100 UTC 6 October 2013 before Fitow (2013) made landfall, the eye of typhoon Fitow is surrounded by relatively complete circular rainbands, and near-solid rings of convections wrap around the Typhoon's center. At 1800 UTC 6 October 2013 after Fitow (2013) made landfall, the organized convections in the eyewall regions dissipated, leaving the circular convections on the northeast side of the eyewall. At 0000 UTC 7 October, the convections are less organized as the Fitow weakened rapidly. From 0600 UTC 7 October to 1200 UTC 7 October 2013, only isolated convective cores can be found. Cellular convections embedded in the spiral rainbands in the stratiform regions. The random distributions of isolated convective rainfall indicate that the small-scale convections prevail in the eyewall regions and spiral rainbands.

\section{SUMMARY}

The convective and stratiform rainfall is separated and analyzed using the 3D WRF model data of typhoon Fitow in 2013. The vertical profiles of vertical velocity and rain microphysical budget are examined for each rain type separated based on surface precipitation budget equation. The three rain types (TFM, TFm, and tFm) possessed water vapor convergence and upward motions throughout the troposphere form convective rainfall. The liquid cloud microphysical processes are dominant in convective rainfall regions where accretion of cloud water by raindrop is the main process responsible for the convective rainfall development. Two rain types (TfM and tfM) generally possess water vapor divergence and downward motions in the lower troposphere and dominant ice microphysical process constitute stratiform rainfall. The rain type tFM is put into stratiform category considering the relatively importance of ice microphysical process and downward motion in the lower troposphere, and the rain type $\mathrm{Tfm}$ is also put into stratiform category considering the similar characteristics to stratiform rainfall. The ice cloud microphysical processes are dominant in stratiform rainfall regions where melting of graupel is the main process responsible for the stratiform rainfall development. The rain type (TFM) connected with water vapor convergence, hydrometeor convergence and atmospheric drying has the maximum rainfall intensity. As indicated by Cui and $\mathrm{Li}$ (2006), the hydrometeor convergence and water vapor convergence in TFM account for $40 \%$ of maximum rainfall, respectively, indicating the importance of hydrometeor convergence in the production of maximum rainfall intensity. However, maximum rainfall is not always connected with maximum water vapor convergence, which may be used to moisten atmosphere and to support hydrometeor divergence. The convective-stratiform rainfall mainly possesses similar characteristics as those separated by Sui et al. (2007) in terms of vertical velocity and cloud microphysical budget.

This study separates convective-stratiform rainfall in a Typhoon case, and further enhances understanding characteristics of convective-stratiform rainfall by conducting CFAD analysis and cloud microphysical budget. Convective-stratiform rainfall separations and statistical results in this study are generally consistent with those in 2D CRM in Li et al. (2014). Generally speaking, the convectivestratiform partitioning from three-dimensional WRF model simulation is generally reasonable in terms of statistics of vertical velocity and cloud microphysics, indicating potential application of budget-based rainfall partitioning method both in 2D CRMs with periodic lateral boundaries and 3D 

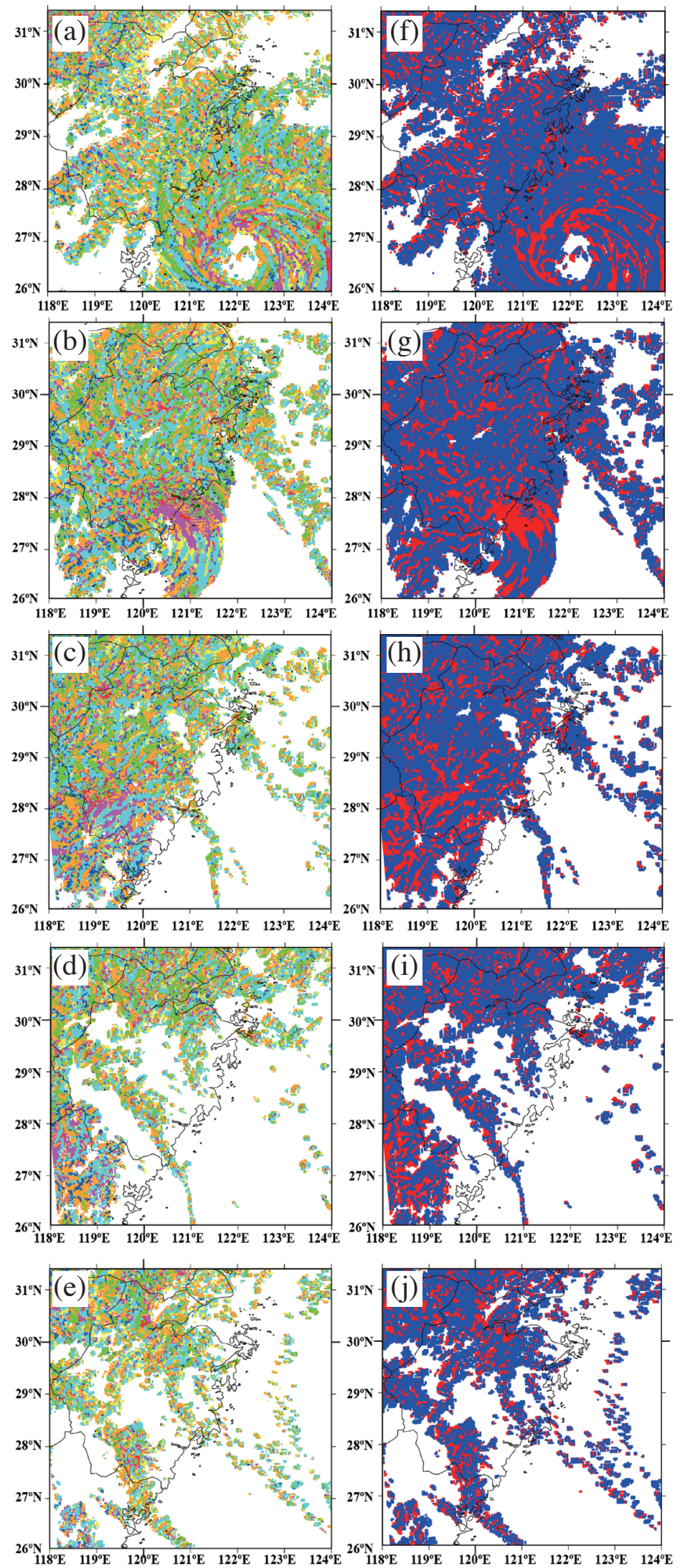

Fig. 6. Spatial distributions of (a), (b), (c), (d), (e) eight rain types for TFM (red), TFm (magenta), tFM (green), tFm (orange), TfM (cyan), Tfm (yellow), tfM (blue), and tfm (black), and (f), (g), (h), (i), (j) for convective rainfall TFM $+\mathrm{TFm}+\mathrm{tFm}$ (red) and stratiform rainfall tFM + Tfm + TfM + tfM (blue) at (a), (f) 1100 UTC 6 October; (b), (g) 1800 UTC 6 October; (c), (h) 0000 UTC 7 October; (d), (i) 0600 UTC 7 October; (e), (j) 1200 UTC 7 October 2013. 
models with open lateral boundaries. This study indicates it may be reasonable to apply the convective-stratiform partitioning algorithm by $\mathrm{Li}$ et al. (2014) to typhoon Fitow (2013) in 3D WRF model, facilitating the examination of the detailed structures and evolution of convective and stratiform rainfall in the typhoon Fitow (2013) rainfall in further studies.

Caution may be exercised since the results in the present study are based on numerical simulations with a case of typhoon employing a traditional single-moment (Purdue-Lin) scheme. In this study, the major microphysics processes used to convective-stratiform rainfall separation is $\mathrm{P}_{\mathrm{GACW}}, \mathrm{P}_{\mathrm{RACW}}$, $\mathrm{P}_{\mathrm{GMLT}}$, since those microphysics processes are dominant in producing rainfall. Huang and Cui (2015) simulated a torrential rainfall event with Milbrandt 2-moment parameterization scheme in the WRF model, and their results showed that accretion of cloud water by raindrop and the accretion of cloud water by graupel, the melting of graupel to form raindrop are major processes, indicating the major microphysical processes in producing rainfall are similar between one-moment Purdue-Lin scheme and Milbrandt 2-moment parameterization scheme. Thus, the separation results may not vary very much when employing an advanced scheme due to the similar major microphysics processes. In further study, more cases using double-moment schemes will be used to generalize the results from this study.

Acknowledgements This work was supported by the National Natural Science Foundation of China (41575042, 41475039, 41775040) and National Key Basic Research and Development Project of China (2015CB953601).

\section{REFERENCES}

Adler, R. F. and A. J. Negri, 1988: A satellite infrared technique to estimate tropical convective and stratiform rainfall. J. Appl. Meteorol., 27, 30-51, doi: 10.1175/15 20-0450(1988)027<0030:ASITTE>2.0.CO;2. [Link]

Anagnostou, E. N., 2004: A convective/stratiform precipitation classification algorithm for volume scanning weather radar observations. Meteorol. Appl., 11, 291300, doi: 10.1017/S1350482704001409. [Link]

Austin, P. M. and R. A. Houze, 1972: Analysis of the structure of precipitation patterns in New England. J. Appl. Meteorol., 11, 926-935, doi: 10.1175/1520-0450(1972 )011<0926:AOTSOP>2.0.CO;2. [Link]

Awaka, J., T. Iguchi, H. Kumagai, and K. Okamoto, 1997: Rain type classification algorithm for TRMM precipitation radar. IGARSS'97, Remote Sensing - A Scientific Vision for Sustainable Development, IEEE, doi: 10.1109/IGARSS.1997.608993. [Link]

Balsley, B. B., W. L. Ecklund, D. A. Carter, A. C. Riddle, and K. S. Gage, 1988: Average vertical motions in the tropical atmosphere observed by a radar wind profiler on Pohnpei $\left(7^{\circ} \mathrm{N}\right.$ latitude, $157^{\circ} \mathrm{E}$ longitude). J. Atmos. Sci., 45, 396-405, doi: 10.1175/1520-0469(1988)045< 0396:AVMITT>2.0.CO;2. [Link]

Bao, X., N. E. Davidson, H. Yu, M. C. N. Hankinson, Z. Sun, L. J. Rikus, J. Liu, Z. Yu, and D. Wu, 2015: Diagnostics for an extreme rain event near Shanghai during the landfall of Typhoon Fitow (2013). Mon. Weather Rev., 143, 3377-3405, doi: 10.1175/MWRD-14-00241.1. [Link]

Biggerstaff, M. I. and S. A. Listemaa, 2000: An improved scheme for convective/stratiform echo classification using radar reflectivity. J. Appl. Meteorol., 39, 21292150, doi: 10.1175/1520-0450(2001)040<2129:AISF CS $>2.0 . C O ; 2$. [Link]

Caniaux, G., J. Redelsperger, and J. Lafore, 1994: A numerical study of the stratiform region of a fast-moving squall line. Part I: General description and water and heat budgets. J. Atmos. Sci., 51, 2046-2074, doi: 10.1175/1520-0 469(1994)051<2046:ANSOTS>2.0.CO;2. [Link]

Chen, S. H. and W. Y. Sun, 2002: A one-dimensional time dependent cloud model. J. Meteorol. Soc. Jpn., 80, 99118, doi: 10.2151/jmsj.80.99. [Link]

Churchill, D. D. and R. A. Houze, 1984: Development and structure of winter monsoon cloud clusters on $10 \mathrm{De}-$ cember 1978. J. Atmos. Sci., 41, 933-960, doi: 10.11 75/1520-0469(1984)041<0933:DASOWM>2.0.CO;2. [Link]

Cui, X. and X. Li, 2006: Role of surface evaporation in surface rainfall processes. J. Geophys. Res., 111, D17112, doi: 10.1029/2005JD006876. [Link]

Dudhia, J., 1989: Numerical study of convection observed during the winter monsoon experiment using a mesoscale two-dimensional model. J. Atmos. Sci., 46, 3077-3107, doi: 10.1175/1520-0469(1989)046<3077: NSOCOD>2.0.CO;2. [Link]

Dudhia, J., 1996: A multi-layer soil temperature model for MM5. The Sixth PSU/NCAR Mesoscale Model Users' Workshop, 22-24.

Gamache, J. F. and R. A. Houze, 1982: Mesoscale air motions associated with a tropical squall line. Mon. Weather Rev., 110, 118-135, doi: 10.1175/1520-0493 (1982) $110<0118$ :MAMAWA > 2.0.CO;2. [Link]

Gao, S., 2007: A three-dimensional dynamic vorticity vector associated with tropical oceanic convection. J. Geophys. Res., 112, doi: 10.1029/2006JD008247. [Link]

Gao, S., X. Cui, Y. Zhou, X. Li, and W.-K. Tao, 2005a: A modeling study of moist and dynamic vorticity vectors associated with two-dimensional tropical convection. J. Geophys. Res., 110, D17104, doi: 10.1029/2004JD005675. [Link]

Gao, S., X. Cui, Y. Zhou, and X. Li, 2005b: Surface rainfall processes as simulated in a cloud-resolving model. J. Geophys. Res., 110, D10202, doi: 10.1029/2004JD005467. [Link] 
Hong, S. Y. and J. O. J. Lim, 2006: The WRF Single-Moment 6-Class Microphysics Scheme (WSM6). AsiaPacific J. Atmos. Sci., 42, 129-151.

Hong, S. Y. and H. L. Pan, 1996: Nonlocal boundary layer vertical diffusion in a medium-range forecast model. Mon. Weather Rev., 124, 2322-2339, doi: 10.1175/152 0-0493(1996)124<2322:NBLVDI>2 .0.CO;2. [Link]

Hong, S. Y., Y. Noh, and J. Dudhia, 2006: A new vertical diffusion package with an explicit treatment of entrainment processes. Mon. Weather Rev., 134, 2318-2341, doi: 10.1175/mwr3199.1. [Link]

Hong, Y., C. D. Kummerow, and W. S. Olson, 1999: Separation of convective and stratiform precipitation using microwave brightness temperature. J. Appl. Meteorol., 38, 1195-1213, doi: 10.1175/1520-0450(1999)038<11 95:SOCASP>2.0.CO;2. [Link]

Houghton, H. G., 1968: On precipitation mechanisms and their artificial modification. J. Appl. Meteorol., 7, 851859, doi: 10.1175/1520-0450(1968)007<0851:OPMATA>2.0.CO;2. [Link]

Houze, R. A., 1973: A climatological study of vertical transports by cumulus-scale convection. J. Atmos. Sci., 30, 1112-1123, doi: 10.1175/1520-0469(1973)030<1112: ACSOVT>2.0.CO;2. [Link]

Huang, H. L., M. J. Yang, and C. H. Sui, 2014: Water budget and precipitation efficiency of typhoon Morakot (2009). J. Atmos. Sci., 71, 112-129, doi: 10.1175/JASD-13-053.1. [Link]

Huang, Y. and X. Cui, 2015: Moisture Sources of Torrential Rainfall Events in the Sichuan Basin of China during Summers of 2009-13. J. Hydrometeorol., 16, 19061917, doi: 10.1175/jhm-d-14-0220.1. [Link]

Johnson, R. H. and P. J. Hamilton, 1988: The relationship of surface pressure features to the precipitation and airflow structure of an intense midlatitude squall line. Mon. Weather Rev., 116, 1444-1473, doi: 10.1175/152 0-0493(1988)116<1444:TROSPF>2.0.CO;2. [Link]

Lang, S., W.-K. Tao, J. Simpson, and B. Ferrier, 2003: Modeling of convective-stratiform precipitation processes: Sensitivity to partitioning methods. J. Appl. Meteorol., 42, 505-527, doi: 10.1175/1520-0450(2003)042<0505 :MOCSPP> 2.0.CO;2. [Link]

Li, X., G. Zhai, S. Gao, and X. Shen, 2014: A new convective-stratiform rainfall separation scheme. Atmos. Sci. Lett., 15, 245-251, doi: 10.1002/asl2.493. [Link]

Lim, K. S. and S. Y. Hong, 2010: Development of an effective double-moment cloud microphysics scheme with prognostic cloud condensation nuclei (CCN) for weather and climate models. Mon. Weather Rev., 138, 1587-1612, doi: 10.1175/2009MWR2968.1. [Link]

Lin, Y. L., R. D. Farley, and H. D. Orville, 1983: Bulk Parameterization of the Snow Field in a Cloud Model. J. Clim. Appl. Meteorol., 22, 1065-1092, doi: 10.1175/15 20-0450(1983)022<1065:BPOTSF>2.0.CO;2. [Link]
Liu, R., G. Zhai, P. Zhu, and L. Li, 2016: The effects of different microphysical schemes in WRF on the rainstorm of typhoon fitow in 2013. Journal of Zhejiang University, 43, 593-600, doi: 10.3785/j.issn.10089497.2016.05.017. (in Chinese) [Link]

Lou, L. and X. Li, 2016: Radiative effects on torrential rainfall during the landfall of Typhoon Fitow (2013). $A d v$. Atmos. Sci., 33, 101-109, doi: 10.1007/s00376-0155139-y. [Link]

Mlawer, E. J., S. J. Taubman, P. D. Brown, M. J. Iacono, and S. A. Clough, 1997: Radiative transfer for inhomogeneous atmospheres: RRTM, a validated correlated-k model for the longwave. J. Geophys. Res., 102, 16663 16682, doi: 10.1029/97JD00237. [Link]

Morrison, H., G. Thompson, and V. Tatarskii, 2009: Impact of Cloud Microphysics on the Development of Trailing Stratiform Precipitation in a Simulated Squall Line: Comparison of One- and Two-Moment Schemes. Mon. Weather Rev., 137, 991-1007, doi: 10.1175/2008MWR2556.1. [Link]

Powell, S. W., R. A. Houze, and S. R. Brodzik, 2016: RainfallType Categorization of Radar Echoes Using Polar Coordinate Reflectivity Data. J. Atmos. Ocean. Technol., 33, 523-538, doi: 10.1175/jtech-d-15-0135.1. [Link]

Rutledge, S. A. and P. V. Hobbs, 1984: The mesoscale and microscale structure and organization of clouds and precipitation in midlatitude cyclones. XII: A diagnostic modeling study of precipitation development in narrow cold-frontal rainbands. J. Atmos. Sci., 41, 2949-2972, doi: 10.1175/1520-0469(1984)041<2949:tmamsa 2.0 . co;2. [Link]

Schumacher, C. and R. A. Houze, 2003: Stratiform rain in the tropics as seen by the TRMM precipitation radar. $J$. Climate, 16, 1739-1756, doi: 10.1175/1520-0442(200 3)016<1739:SRITTA $>2.0 . C O ; 2$. [Link]

Shen, X., Y. Wang, N. Zhang, and X. Li, 2010: Precipitation and cloud statistics in the deep tropical convective regime. J. Geophys. Res., 115, doi: 10.1029/2010JD014481. [Link]

Skamarock, W. C., J. B. Klemp, J. Dudhia, D. O. Gill, D. M. Barker, M. G. Duda, X. Y. Huang, W. Wang, and J. G. Powers, 2008: A description of the Advanced Research WRF version 3. NCAR Technical Note NCAR/ TN-475+STR, National Center for Atmospheric Research, Boulder, Colorado, USA, 113 pp, doi: 10.5065/ D68S4MVH. [Link]

Steiner, M. and R. A. Houze, 1993: Three-dimensional validation at TRMM ground truth sites: Some early results from Darwin, Australia. 26th International Conference on Radar Meteorology, Norman, OK, 417-420.

Steiner, M., R. A. Houze, and S. E. Yuter, 1995: Climatological characterization of three-dimensional storm structure from operational radar and rain gauge data. $J$. Appl. Meteorol., 34, 1978-2007, doi: 10.1175/1520-04 
50(1995)034<1978:CCOTDS>2.0.CO;2. [Link]

Stephens, G. L., S. Van Den Heever, and L. Pakula, 2008: Radiative-convective feedbacks in idealized states of radiative-convective equilibrium. J. Atmos. Sci., 65, 3899-3916, doi: 10.1175/2008JAS2524.1. [Link]

Sui, C. H. and X. Li, 2005: A tendency of cloud ratio associated with the development of tropical water and ice clouds. Terr. Atmos. Ocean. Sci., 16, 419-434, doi: 10.3319/TAO.2005.16.2.419(A). [Link]

Sui, C. H., K. M. Lau, W. K. Tao, and J. Simpson, 1994: The tropical water and energy cycles in a cumulus ensemble model. Part I: Equilibrium climate. J. Atmos. Sci., 51, 711-728, doi: 10.1175/1520-0469(1994)051< 0711:TTWAEC>2.0.CO;2. [Link]

Sui, C. H., C. T. Tsay, and X. Li, 2007: Convective-stratiform rainfall separation by cloud content. J. Geophys. Res., 112, doi: 10.1029/2006JD008082. [Link]

Tao, W. K. and J. Simpson, 1989: Modeling study of a tropical squall-type convective line. J. Atmos. Sci., 46, 177202, doi: 10.1175/1520-0469(1989)046<0177:MSOA TS>2.0.CO;2. [Link]

Tao, W. K. and S. T. Soong, 1986: A study of the response of deep tropical clouds to mesoscale processes: Threedimensional numerical experiments. J. Atmos. Sci., 43, 2653-2676, doi: 10.1175/1520-0469(1986)043<2653: ASOTRO $>2.0 . C O ; 2$. [Link]

Tao, W. K., J. Simpson, and S. T. Soong, 1987: Statistical properties of a cloud ensemble: A numerical study. $J$. Atmos. Sci., 44, 3175-3187, doi: 10.1175/1520-0469(1 987)044<3175:SPOACE $>2.0 . C O ; 2$. [Link]

Tao, W. K., J. Simpson, and M. McCumber, 1989: An icewater saturation adjustment. Mon. Weather Rev., 117, 231-235, doi: 10.1175/1520-0493(1989)117<0231:AIWSA $>2.0 . C O ; 2$. [Link]

Tao, W. K., J. Simpson, C. H. Sui, B. Ferrier, S. Lang, J. Scala, M. D. Chou, and K. Pickering, 1993: Heating, moisture, and water budgets of tropical and midlatitude squall lines: Comparisons and sensitivity to longwave radiation. J.Atmos. Sci., 50, 673-690, doi: 10.1175/152 0-0469(1993)050<0673:HMAWBO>2.0.CO;2. [Link]

Tao, W. K., S. Lang, J. Simpson, W. S. Olson, D. Johnson, B. Ferrier, C. Kummerow, and R. Adler, 2000: Vertical Profiles of Latent Heat Release and Their Retrieval for TOGA COARE Convective Systems using a Cloud Resolving Model, SSM/I, and Ship-borne Radar Data. J. Meteorol. Soc. Jpn., 78, 333-355, doi: 10.2151/ jmsj1965.78.4_333. [Link]

Thompson, G., P. R. Field, R. M. Rasmussen, and W. D. Hall, 2008: Explicit forecasts of winter precipitation using an improved bulk microphysics scheme. Part II: Implementation of a new snow parameterization. Mon. Weather Rev., 136, 5095-5155, doi: 10.1175/2008MWR2387.1. [Link]
Williams, C. R., W. L. Ecklund, and K. S. Gage, 1995: Classification of precipitating clouds in the tropics using 915-MHz wind profilers. J. Atmos. Ocean. Technol., 12, 996-1012, doi: 10.1175/1520-0426(1995)012<099 6:COPCIT>2.0.CO;2. [Link]

$\mathrm{Xu}, \mathrm{H}$. and X. Li, 2017: Torrential rainfall processes associated with a landfall of Typhoon Fitow (2013): A threedimensional WRF modeling study. J. Geophys. Res., 122, 6004-6024, doi: 10.1002/2016JD026395. [Link]

Xu, H., R. Liu, G. Zhai, and X. Li, 2016: Torrential rainfall responses of Typhoon Fitow (2013) to radiative processes: A three-dimensional WRF modeling study. J. Geophys. Res., 121, 14127-14136, doi: 10.1002/2016JD025479. [Link]

Xu, H., G. Zhai, and X. Li, 2017: Precipitation Efficiency and Water Budget of Typhoon Fitow (2013): A Particle Trajectory Study. J. Hydrometeorol., 18, 23312354, doi: 10.1175/jhm-d-16-0273.1. [Link]

Xu, K. M., 1995: Partitioning mass, heat, and moisture budgets of explicitly simulated cumulus ensembles into convective and stratiform components. J. Atmos. Sci., 52, 551-573, doi: 10.1175/1520-0469(1995)052<0551 :PMHAMB $>2.0 . \mathrm{CO} ; 2$. [Link]

Xu, K. M., R. T. Cederwall, L. J. Donner, W. W. Grabowski, F. Guichard, D. E. Johnson, M. Khairoutdinov, S. K. Krueger, J. C. Petch, D. A. Randall, C. J. Seman, W. K. Tao, D. Wang, S. C. Xie, J. J. Yio, and M. H. Zhang, 2002: An intercomparison of cloudresolving models with the Atmospheric Radiation Measurement summer 1997 Intensive Observation Period data. Q. J. R. Meteorol. Soc., 128, 593-624, doi: 10.1256/003590002321042117. [Link]

Yang, M. J., D. L. Zhang, and H. L. Huang, 2008: A modeling study of Typhoon Nari (2001) at landfall. Part I: Topographic effects. J. Atmos. Sci., 65, 3095-3115, doi: 10.1175/2008JAS2453.1. [Link]

Yang, M. J., S. A. Braun, and D. S. Chen, 2011: Water Budget of Typhoon Nari (2001). Mon. Weather Rev., 139, 3809-3828, doi: 10.1175/MWR-D-10-05090.1. [Link]

Yang, Y., X. Chen, and Y. Qi, 2013: Classification of convective/stratiform echoes in radar reflectivity observations using a fuzzy logic algorithm. J. Geophys. Res., 118, 1896-1905, doi: 10.1002/jgrd .50214. [Link]

Yu, Z., Y. Chen, D. Wu, G. Chen, X. Bao, Q. Yang, R. Yu, L. Zhang, J. Tang, M. Xu, and Z. Zeng, 2014: Overview of severe typhoon Fitow and its operational forecasts. Tropical Cyclone Research and Review, 3, 22-34, doi: 10.6057/2014TCRR01.02. [Link]

Yuter, S. E. and R. A. Houze, 1997: Measurements of raindrop size distributions over the Pacific warm pool and implications for Z-R relations. J. Appl. Meteorol., 36, 847-867, doi: 10.1175/1520-0450(1997)036<0847:M ORSDO>2.0.CO;2. [Link] 